\title{
CINCO AÑOS DE ESCRITORAS EN EL ALMANAQUE ILUSTRADO DEL URUGUAY: ÍNDICE BIBLIOGRÁFICO
}

\section{Five Years of Female Writers in the Almanaque Ilustrado del Uruguay: Bibliographic Index}

\author{
AlmudenA MejÍAs AlONSO \\ Universidad Complutense de Madrid \\ amejias@ucm.es \\ ORCID ID: 0000-0001-6793-4711 \\ ISABEL CRISTINA DíEZ MÉNGUEZ \\ Universidad Complutense de Madrid \\ icdiezme@filol.ucm.es \\ ORCID ID: 0000-0001-9439-4773
}

Recibido: 05-12-2020 / Aceptado: 7-10-2021 DOI: https://doi.org/10.51743/cilh.vi46.179

RESUMEN El Almanaque Ilustrado del Uruguay es un ejemplo de la presencia, cada vez más sólida, de la mujer en la literatura en el Uruguay de principios de siglo. Este «Índice bibliográfico» da constancia de la labor de mujeres como Delmira Agustini, María Eugenia Vaz Ferreira, Gala Placidia o Clotilde Luisi, que conviven en la revista con autores consagrados como Julio Herrera y Reissig o Rubén Darío.

PALABRAS CLAVE: revistas; Uruguay; índice bibliográfico; mujer; literatura.

ABSTRACT

The Almanaque Ilustrado del Uruguay is an example of the increasingly solid presence of women in literature in Uruguay at the turn of the century. This «Bibliographic Index» shows the work of women as Delmira Agustini, María Eugenia Vaz Ferreira, Gala Placidia or Clotilde Luisi, who coexist in the magazine with the already consecrated authors like Julio Herrera y Reissig or Rubén Darío.

KEYWORDS: Magazines; Uruguay; Bibliographic Index; Women; Literature. 


\title{
CINCO AÑOS DE ESCRITORAS EN EL ALMANAQUE ILUSTRADO DEL URUGUAY: ÍNDICE BIBLIOGRÁFICO ${ }^{1}$
}

\author{
Almudena MejÍAs AlONSO \\ ISABEL CRISTINA DÍEZ MÉNGUEZ \\ Universidad Complutense de Madrid
}

FUE RICARDO SÁNCHEZ el fundador y director del Almanaque Ilustrado del Uruguay, que se editó en Montevideo en la Imprenta Artística y Encuadernación de Juan J. Dornaleche [Rocca, 2012: 10] desde 1904 a 1919. Con una cuidada encuadernación, la cubierta se presenta en cartoné cromolitografiado y la mujer va a ser el motivo central que unifique el conjunto de los Almanaques: con el título «Galería de bellezas» se insertan entre sus páginas retratos e imágenes de mujeres montevideanas, algunas de ellas anónimas y en otras ocasiones de figuras destacadas del mundo intelectual uruguayo.

Encontramos en el Almanaque el gusto por la decoración modernista. A lo largo de sus páginas, y junto a los anuncios de los inventos más recientes, como el fonógrafo, y de las mejores marcas de café, vino de Burdeos, champagne o aceites franceses, se encuentran los

\footnotetext{
${ }^{1}$ «Cinco años de escritoras en el Almanaque Ilustrado del Uruguay: Índice bibliográfico» es un trabajo vinculado al Proyecto de investigación I+D «Las revistas del modernismo hispánico. Bases de datos para una colaboración entre dos continentes», FFI2013-48178-C2-1-P, dirigido por la profesora Rocío Oviedo Pérez de Tudela.
} 
productos de belleza femeninos, donde la imagen de la mujer es el motivo recurrente.

Sobresalen los remates y cabeceras que embellecen las páginas literarias y las orlas a base de líneas sinuosas y motivos geométricos y vegetales dispuestos con carácter simétrico que enmarcan los numerosos anuncios intercalados, impresos en ocasiones sobre papel de color rosa, amarillo, rojo o naranja. La gran variedad tipográfica se distingue de nuevo en los anuncios, frente a la letra clara, sencilla y elegante del texto.

El Almanaque Ilustrado del Uruguay se manifiesta como un reflejo del ambiente intelectual del Montevideo de comienzos del siglo XX, que se movía entre lo establecido y las nuevas ideas renovadoras [Medina Vial, 1973: 57-71] $]^{2}$ Y ahí es donde van a encontrar su lugar las voces femeninas, entre las que destacarán las ya consagradas Delmira Agustini y María Eugenia Vaz Ferreira junto a otras, no tan conocidas aún, como María Clotilde Artigalá y Herminia Sierra de los Santos, que empiezan a abrirse paso en la sociedad ${ }^{3}$.

Los ejemplares que nos ocupan, los publicados entre 1909 y 1913 , ofrecen un rico panorama de las letras femeninas uruguayas de principios del siglo XX. Entre las escritoras rioplatenses contemporáneas presentes, la que colaboró de forma constante fue Delmira Agustini, de quien hallamos una composición poética en cada uno de los almanaques de estos años; también cabe destacar en estos años la presencia de María Clotilde Artigalá, Gala Placidia o Clotilde Luisi.

Hay que tener en cuenta las siguientes observaciones:

1. Este trabajo no constituye un vaciado completo del Almanaque Ilustrado del Uruguay, dado que nuestro interés es extraer la información sobre las escritoras hispa-

\footnotetext{
${ }^{2}$ Véase también al respecto Sarah Bollo [1951].

${ }^{3}$ De hecho, Herminia Sierra fue la primera mujer matriculada en los cursos de Notariado y la primera graduada como Escribana Pública.
} 
noamericanas cuya obra aparece en el Almanaque en los años reseñados.

2. El índice de autoras que colaboran en el Almanaque se ha organizado por orden alfabético, numerando correlativamente cada una de las fichas.

3. Cuando en el Almanaque solo constan las iniciales (o el nombre incompleto) y se conoce su correspondencia, la información se consigna entre corchetes.

4. En algún caso, a continuación de la ficha principal puede aparecer una Nota aclaratoria de las autoras de este Índice.

5. Para mayor eficacia se ha incluido un Índice onomástico en el que se registran todos los nombres propios que aparecen y un Índice de títulos y primeros versos contenidos en las 33 fichas, a cuyo número se remite.

\section{ÍNDICE BIBLIOGRÁFICO}

1. ACEVEDO, Virginia

«Impresiones y recuerdos»

Almanaque Ilustrado del Uruguay, 1909, pp. 39-40

2. -

«Ausencia». A Josefina

[«iOh, qué triste está el colegio!...»]

Almanaque Ilustrado del Uruguay, 1909, pp. 216-217

3. -

«Olvido». Para ti

[«En el nublado que causó tu olvido...»]

Almanaque Ilustrado del Uruguay, 1910, p. 68 
4. Agustini, Delmira ${ }^{4}$

«A una cruz. Exvoto»

[ «Cruz que ofrendando tu infinito abrazo...»]

Almanaque Ilustrado del Uruguay, 1909, pp. 59-60

Nota: Poema incluido en Cantos de la mañana (1910) y en Los astros del abismo, tomo II de las Obras Completas editadas en 1924. En la p. 57 se inserta un retrato de la autora.

5. -

«Sueño egoísta»

[«La intensa realidad de un sueño lúgubre...»]

Almanaque Ilustrado del Uruguay, 1909, p. 145

Nota: Poema incluido, sin título, en Cantos de la mañana (1910) y en

Los astros del abismo, tomo II de las Obras Completas editadas en 1924.

6. -

«De una confesión»

«¿Cuál es el hombre que ha hecho más bien a la humanidad?»

[«Ante un vértigo helante de la vida...»]

«¿QQué ojos prefiere usted?»

[«Ojos cansados, ojos tristes, ojos...»]

«¿QQué país prefiere usted habitar?»

[«Un rincón del Oriente, una comarca...»]

\footnotetext{
${ }^{4}$ Delmira Agustini. Nació en Montevideo en 1886. Poeta modernista, forma parte de la denominada «Generación del 900» junto a nombres como Julio Herrera y Reissig, $M^{a}$ Eugenia Vaz Ferreira y Horacio Quiroga. Colaboró en las distintas revistas literarias uruguayas del momento. A su muerte, en 1914, se habían editado tres de sus libros de poemas: El libro blanco [Bertani, 1907], Cantos de la mañana [Bertani, 1910] y Los cálices vacíos [Bertani, 1913]. Póstumamente se imprimieron El rosario de Eros [Maximino García, 1924], tomo I de las Obras completas, donde se incluyen poemas inéditos que la autora fue agrupando, según los escribía, entre los años 1913 y 1914, con el mismo título de este libro y Los astros del abismo [Maximino García, 1924], tomo II de las Obras completas, donde se incluyen, bajo el título de «La Alborada», poemas de infancia de la autora. Murió, asesinada por su exmarido, en 1914.
} 
«¿Qué personaje de novela o de teatro?»

[«Bergerac - redivivo en el diseño...»]

«¿Cree usted que la dicha exista?»

[ «Como la espuma, en gasas tembladoras,...»]

«¿Cuál es, según usted, el ideal de la dicha terrestre?»

[«La torre del Ensueño, las vidrieras...»]

«¿Cuál es su principal esperanza?»

[«... Nací en las cumbres de la vida, trágicas,...»]

«¿Qué animal le es a usted más simpático?»

[«Sonrisa de los cielos bajo el ceño...»]

«¿Qué vicio detesta usted más?»

[«¿Enfermedad del alma?... ¿ley suprema?...»]

«¿Le gusta a usted la poesía?»

[«iMi torre de marfil, mi vida entera!...»]

Almanaque Ilustrado del Uruguay, 1910, pp. 197- 199

Nota: Estos versos forman parte de un todo más extenso que aparece en el Cuaderno 3 de los Manuscritos de Delmira ${ }^{5}$. Es un cuestionario de preguntas con su respuesta (si la hay) en verso; abarca del folio $50 \mathrm{r}$ al $57 \mathrm{r}$.

\section{7. -}

«En tus ojos»

[«iOjos a toda luz y a toda sombra!...»]

\footnotetext{
${ }^{5}$ Está digitalizado por la Biblioteca Nacional de Uruguay y se encuentra en el sitio «Archivo de Delmira Agustini». Véase

http://archivodelmira.bibna.gub.uy/omeka/items/show/103 [Consultado el 2 de septiembre de 2020]. El mismo formato lo encontramos en el poemario Aleteos de María H. Sabbia, otra de las autoras que aparecen en este Almanaque. Véase María Herminia Sabbia y Oribe (1898): Aleteos (Montevideo, Tipografía de La Tribuna Popular), 61-67.
} 
Almanaque Ilustrado del Uruguay, 1911, pp. 81-82

Nota: Poema fechado al final en «1909». Incluido en 1913 en Los

Cálices Vacíos. Se acompaña con un retrato de la autora.

8. -

«La ruptura»

[ «Érase una cadena fuerte como un destino,...»]

Almanaque Ilustrado del Uruguay, 1912, p. 74

Nota: Poema que aparecerá en 1913 en Los Cálices vacíos.

9. -

«Supremo idilio». (Boceto de un poema)

[«En el balcón romántico de un castillo adormido...»]

Almanaque Ilustrado del Uruguay, 1913, pp. 19-22

Nota: Poema que ya había sido publicado en 1910, en Cantos de la

Mañana.

10. ARTigalá, María Clotilde [del Carmen] ${ }^{6}$

«La cuerda rota»

Almanaque Ilustrado del Uruguay, 1909, pp. 61-64.

Nota: Fechado al final del relato en «Otoño de 1908».

11. -

«La medalla»

Almanaque Ilustrado del Uruguay, 1910, pp. 126-131

Nota: Fechado al final del relato en «Otoño del 1909».

12. -

«Samaritana»

Almanaque Ilustrado del Uruguay, 1911, pp. 103-105

Nota: Fechado al final del relato en «1910».

13. -

«El regalo de los Reyes»

Almanaque Ilustrado del Uruguay, 1912, pp. 16-18

Nota: Fechado al final del relato en «Agosto de 1911».

\section{GALA PLACIDIA ${ }^{7}$}

\footnotetext{
${ }^{6}$ María Clotilde Artigalá. 1870-1930.
} 
«Pueblos hermanos»

Almanaque Ilustrado del Uruguay, 1909, pp. 109-112

Nota: En la p. 107 aparece un retrato de la autora y su nombre real.

15. -

«Algunos pensamientos»

Almanaque Ilustrado del Uruguay, 1909, pp. 170-171

16. -

«Vidalitas»

[«Una ola perdida,...»]

Almanaque Ilustrado del Uruguay, 1909, p. 212

17. GIANNETTO, Clara $^{8}$

«Une sirène chanta (sic) la Beauté». A la excelsa poeta María Eugenia Vaz Ferreira

[ On me dit d'une sirène...»]

Almanaque Ilustrado del Uruguay, 1909, pp. 218-219

18. INCÓGNITA, Modesta

«En Atahualpa. (Recuerdos infantiles)»

Almanaque Ilustrado del Uruguay, 1910, pp. 140-144

19. LIS, Noemia de

«El vagamundo y su alma». (Del Álbum de Pedro Parrabere')

${ }^{7}$ Gala Placidia. Pseudónimo de Martha Costa de Carril. Colaboradora de El Siglo, La Razón, el Diario del Plata y la Revista Uruguay, a veces firma sus textos con pseudónimos como Gala Placidia, Mlle. Petronio y Tía Clara. Con el trabajo «Sobre feminismo: La madre» obtuvo, en 1908, el primer premio en el concurso literario de la Biblioteca de Mujeres de Buenos Aires. Fue publicado ese mismo año en Montevideo, por Barreiro y Ramos.

${ }^{8}$ Clara Giannetto. Alguno de sus poemas aparece en El Parnaso Oriental. Antología de poetas uruguayos, de Raúl Montero Bustamante [1905: 371], concretamente el titulado "A él», que ya había aparecido en el número 3 de la Revista Literaria, correspondiente al 1 de junio de 1900.

${ }^{9}$ Pedro Parrabere. Podría ser Arnaldo Pedro Parrabere, nacido en Francia, pero residente desde niño en Uruguay. Fue miembro de la Comisión Directiva de la Sociedad de Confraternidad Vasca Euskal Erria, de Montevideo y redactor del periódico de la Sociedad, el Euskal Erria. 
Almanaque Ilustrado del Uruguay, 1911, p. 94

Nota: Fechado al final del texto en «Buenos Aires, 22 - XII - 1909».

20. LUISI [de Podestá], Clotilde ${ }^{10}$

«Un deseo»

[«Yo quiero, para el día de mi muerte,...»]

Almanaque Ilustrado del Uruguay, 1909, p. 129

Nota: Fechado al final del poema en «1908». En la página anterior se inserta un retrato de la autora.

21. -

«Primavera»

[«Bendito el sol que con sus rayos finos...»]

Almanaque Ilustrado del Uruguay, 1909, pp. 219-220.

22. -

«Verano»

[«Llueve. La tierra, cálida y reseca,...»]

Almanaque Ilustrado del Uruguay, 1909, pp. 220

Nota: Fechado al final del poema en «1908».

23. OrTicocheA, María ${ }^{11}$

«Naufragio!...»

Almanaque Ilustrado del Uruguay, 1910, pp. 159-161

Nota: Debajo del nombre de la autora, al final del relato, se explicita que es «Alumna del 'Liceo Franco-Uruguayo'». Está fechado en «Octubre de 1909».

24. -

«Nubes!...»

\footnotetext{
${ }^{10}$ Clotilde Luisi. Nacida en 1882, fue la primera mujer titulada como abogado (1911). Al año siguiente formó parte del cuerpo docente de esa facultad. Fundó la Universidad para Mujeres, de Montevideo. Casada con el escritor José María Podestá, los dos ejercieron cargos diplomáticos. Colaboradora en las revisitas literarias rioplatenses, escribió cuentos, poemas y obras de teatro. Murió en Roma en 1969.

${ }^{11}$ María Orticochea. Nacida en 1891, fue una de las alumnas del Liceo Franco Uruguayo, institución en la que se graduó de maestra en 1916. Ejerció la docencia y llegó a ser directora de los Institutos Normales para Señoritas. Murió en 1958.
} 
Almanaque Ilustrado del Uruguay, 1911, pp. 149-152

25. ROVIRA [de Ricci], Tula ${ }^{12}$

«Mis ideas»

Almanaque Ilustrado del Uruguay, 1910, p. 203

Nota: En la p. 201 se inserta un retrato de la autora y se la define como «Doctora en Medicina y Cirugía».

26. SABBIA Y ORIBE, María H[erminia ${ }^{13}$

«A Maruja Blanco Acevedo ${ }^{14}{ }$.

[«Delante del espacio sin límites, delante...»]

Almanaque Ilustrado del Uruguay, 1910, p. 120

27. SAINT-Hilaire de LAMAS, María ${ }^{15}$

«La niña y la muñeca»

Almanaque Ilustrado del Uruguay, 1911, pp. 158-160

Nota: Fechado al final del texto en «Montevideo, Octubre 11 de 1910».

28. SieRra DE LOS SANTOS [de Mattos], Herminia ${ }^{16}$

12 Tula Rovira. Graduada en mayo de 1909, trabajó en el Hospital Maciel y en el Asilo de Huérfanos y llegó a ser Jefe de Clínica del Hospital de Caridad. Casada con el doctor Serafín Ricci, se empeñó en la construcción de un Policlínico y un Hospital para Niños.

${ }^{13}$ María Herminia SABbia y Oribe. Nacida en 1883. Escribió un libro de poemas (el único) titulado Aleteos y publicado en 1898, La Tribuna Popular. Montevideo. Colaboró en las más prestigiosas revistas literarias uruguayas. Algunos de sus textos («Lidia» y «Navidad», que no forman parte del poemario de 1898) aparecieron antologados en El Parnaso Oriental. Antología de poetas uruguayos, de Raúl Montero Bustamante [1905: 326-327]. Murió en 1961.

${ }^{14}$ Maruja Blanco ACEVEdo fue la esposa del poeta Julio Raúl Mendilharsu, amigos muy cercanos de los también poetas Juan Parra del Riego y Blanca Luz Brum.

${ }^{15}$ MARÍA SAINT-HiLAIRE DE LAMAS. Ejerció como maestra. Ella fue quien preparó al futuro escritor Felisberto Hernández para su examen de ingreso en Bachillerato. 
«Ollantay»

Almanaque Ilustrado del Uruguay, 1912, pp. 115-119

Nota: Fechado al final del relato en «Invierno de 1911».

29. TORRES FRÍAS, María ${ }^{17}$

«Primavera»

[«Torna la reina de las tardes áureas,...»]

Almanaque Ilustrado del Uruguay, 1909, pp. 209-211

Nota: Al final del poema, debajo del nombre, han consignado «Argentina».

30. VAZ FERREIRA, María Eugenia ${ }^{18}$

«Triunfal»

[«Bardo gentil de rimas aurorales...»]

Almanaque Ilustrado del Uruguay, 1911, pp. 23-24

Nota: En la p. 21 se inserta un retrato de la autora. El poema había sido publicado con anterioridad en el primer número de La Revista, dirigida por Julio Herrera y Reissig (20 de agosto de 1899). No aparece en La Isla de los Cánticos, edición póstuma de sus poemas que terminó de preparar su hermano Carlos en 1925; ni en La otra Isla de los Cánticos (Montevideo, 1959), recopilación de poemas inéditos a cargo de Emilio Oribe. Pero sí en El Parnaso Oriental, la antología de poetas uruguayos preparada por Raúl Montero Bustamante y publicada en Montevideo en 1905 (p. 308).

31. -

«Primavera»

\footnotetext{
${ }^{16}$ Herminia SierRa DE LOS SANTOS (1888) fue la primera mujer que se graduó de Escribana Pública en Uruguay.

${ }^{17}$ MARÍA TORRES FríAS. Argentina, nacida en Salta en 1877, muy buena parte de su vida residió en Uruguay. Murió en 1954.

${ }^{18} \mathrm{M}^{a}$ EUGENIA VAZ FERREIRA. Fue una de las más importantes poetas uruguayas. Nacida en 1875, pertenece a la llamada "Generación del 900», siendo contemporánea de Delmira Agustini y amiga de Julio Herrera y Reissig, otro de los grandes nombres literarios del Modernismo uruguayo. Colaboró en las más prestigiosas revistas literarias de su tiempo. Ejerció también como profesora de literatura en la Universidad de Mujeres, de Montevideo, fundada por Clotilde Luisi.
} 
[«Tú, Primavera, que eres la diosa de los retoños;...»]

Almanaque Ilustrado del Uruguay, 1912, pp. 107-108

Nota: El poema había sido publicado con anterioridad en el no 3 (20 de septiembre de 1899) de La Revista, dirigida por Julio Herrera y Reissig. No aparece en La Isla de los Cánticos, edición póstuma de sus poemas que terminó de preparar su hermano Carlos en 1925; pero sí en La otra Isla de los Cánticos (Montevideo, 1959, pp. 83-84), recopilación de poemas inéditos a cargo de Emilio Oribe.

\section{ÍNDICE ONOMÁSTICO}

ACEVEDO, Virginia.- 1, 2, 3

Agustini, Delmira. - 4, 5, 6,7, 8, 9

ARTigalÁ, Ma Clotilde [del Carmen]. - 10, 10n, 11, 12, 13,

BLANCO ACEVEDO, Maruja. - 26, 26n

BRUM, Blanca Luz. - 26n

Costa DE CARril, Martha. - Véase GALA Placidia

GALA PLACIDIA. - 14, 14n, 15, 16

GIANNETTO, Clara. - 17, 17n

HERNÁNDEZ, Felisberto. - 27n

HERRERA Y REISSIG, Julio. - 4n, 32, 32n, 33.

INCÓGNITA, Modesta. - 18

LIS, Noemia de. -19

LUISI [de PODESTÁ], Clotilde. - 20, 20n, 21, 22, 32n

MENDILHARSU, Julio Raúl. - 26n

Mlle. Petronio. - Véase Costa de CARril, Martha

MONTERo Bustamante, Raúl. - 17n, 26n, 32

ORIBE, Emilio. - 32, 33

OrticocheA, María. -23, 23n, 24

PARRA DEL RIEGO, Juan. - 26n

PARRABERE, Pedro. $-19,19 n$

PODESTÁ, José María. - 20n

QUIROGA, Horacio. - 4n 
RICCI, Serafín. - 25n

ROVIRA [de Ricci], Tula. $-25,25 n$

SABBIA Y ORIBE, María H[erminia]. - 6n, 26, 26n

SAINT-HILAIRE DE LAMAS, María. - 27, 27n

SIERRA DE LOS SANTOS, Herminia. - 28, 28n

TÍA ClarA. - Véase COSTA DE CARRIL, Martha

TORRES FrÍAS, María. - 29, 29n

VAZ FERREIRA, Carlos. - 32, 33

VAZ FERREIRA, María Eugenia. - 4n, 17, 30, 30n, 31.

\section{ÍNDICE DE TÍTULOS}

«A Maruja Blanco Acevedo». - 26

«A una cruz. Exvoto». - 4

«Alborada (La)». - 4n

«Algunos pensamientos». - 15

Astros (Los) del abismo. - 4, 4n, 5

«Ausencia». - 2

Cálices vacíos (Los). - 4n, 7, 8

Cantos de la mañana. - 4, 4n, 5, 9

«Cuerda rota $(\mathrm{La}) » .-10$

«De una confesión». - 6

«En Atahualpa. (Recuerdos infantiles)». - 18

«En tus ojos». -7

«Impresiones y recuerdos». - 1

Isla de los Cánticos (La) . - 32, 33

Libro blanco (El). $-4 \mathrm{n}$

Manuscritos [de Delmira Agustini]. - 6

«Medalla (La)». - 11

«Mis ideas». -25

«Niña (La) y la muñeca». -27

Otra (La) Isla de los Cánticos. - 32, 33

«La ruptura». -8

«Naufragio!...». - 23 
«iNubes!...». -24

«Ollantay». -30

«Olvido». -3

Parnaso Oriental (El). Antología de poetas uruguayos. - 17n, 26n, 32

«Primavera». - 21, 31, 33.

«Pueblos hermanos». - 14

«Regalo (El) de los Reyes». - 13

Rosario (El) de Eros. - 4n

«Samaritana». - 12

«Sobre feminismo: La madre». - 14n

«Sueño egoísta». -5

«Supremo idilio». -9

«Triunfal». -32

«Un deseo». -20

«Une sirène chanta (sic) la Beauté». - 17

«Vagamundo (El) y su alma». - 19

«Verano». -22

«Vidalitas». - 16

\section{ÍNDICE DE PRIMEROS VERSOS}

«Ante un vértigo helante de la vida...». - 6

«Bardo gentil de rimas aurorales...». -32

«Bendito el sol que con sus rayos finos...». -21

«Bergerac - redivivo en el diseño...». - 6

«Como la espuma, en gasas tembladoras,...». -6

«Cruz que ofrendando tu infinito abrazo...». -4

«Delante del espacio sin límites, delante...».-26

«En el balcón romántico de un castillo adormido...». - 9

«En el nublado que causó tu olvido...». - 3

«¿Enfermedad del alma?... ¿̇ley suprema?...». - 6

«Érase una cadena fuerte como un destino,...». -8

«La intensa realidad de un sueño lúgubre...». - 5

«La torre del Ensueño, las vidrieras...». - 6 
«Llueve. La tierra, cálida y reseca,...». - 22

«iMi torre de marfil, mi vida entera!...». - 6

«Nací en las cumbres de la vida, trágicas,...». - 6

«iOh, qué triste está el colegio!...». - 2

«iOjos a toda luz y a toda sombra!...». - 7

«Ojos cansados, ojos tristes, ojos...». - 6

«On me dit d'une sirène...». - 17

«Sonrisa de los cielos bajo el ceño...». -6

«Torna la reina de las tardes áureas,...». - 31

«Tú, Primavera, que eres la diosa de los retoños;...». - 33

«Un rincón del Oriente, una comarca...». - 6

«Una ola perdida,...». - 16

«Yo quiero, para el día de mi muerte,...». - 20

\section{CONCLUSIONES}

El Almanaque Ilustrado del Uruguay es un ejemplo de la presencia cada vez mayor de la mujer en la prensa periódica uruguaya de principios del siglo XX. Entre los años 1909 y 1913 vieron la luz un total de treinta y un escritos salidos de la pluma de mujeres, siendo el Almanaque de 1909 el que registra un mayor número de colaboraciones femeninas, hasta doce. A partir de este año el número de contribuciones va decreciendo a siete en 1910, seis en 1911 y cinco en 1912. En 1913 solo hallamos la presencia de una aportación.

Por otro lado, de las quince escritoras rioplatenses que participan en el Almanaque Ilustrado del Uruguay entre 1909 y 1913, el mayor número de escritos pertenecen por este orden a Delmira Agustini, con la publicación de seis poemas distribuidos de forma correlativa desde el almanaque de 1909; María Clotilde Artigalá, con cuatro colaboraciones repartidas en los almanaques de 1909, 1910, 1911 y 1912; María Eugenia Vaz Ferreira, Gala Placidia y Virginia Acevedo con tres contribuciones cada una y Clotilde Luisi y María Orticochea 
que insertan dos textos en los almanaques de 1909 la primera y en los de 1910 y 1911 la segunda. El resto de autoras, siete en total, Clara Giannetto, Modesta Incógnita, Noemia de Lis, Tula Rovira, María Sabbia y Oribe, María Herminia Saint-Hilaire de Lamas y Herminia Sierra de los Santos, intervienen con un solo texto entre los años 1909 y 1912.

Todas estas autoras son un claro exponente de la literatura uruguaya de la época.

\section{BIBLIOGRAFÍA}

AGUSTINI, Delmira (1907): El libro blanco, Montevideo, Bertani. (1910): Cantos de la mañana, Montevideo, Bertani. (1913): Los cálices vacíos, Montevideo, Bertani. (1924): El rosario de Eros, Montevideo, Maximino García. (1924): Los astros del abismo, Montevideo, Maximino García.

ARCHIVO de Delmira Agustini.

http://archivodelmira.bibna.gub.uy/omeka/items/show/103. [Consultado el 2 de septiembre de 2020].

BENGLIO BRITO, Raúl (1951): Herrera y Reissig: del modernismo a la vanguardia, Montevideo, Universidad de La República.

BOLlo, Sarah (1951): El modernismo en el Uruguay, Montevideo, [s.n.].

CRISPO ACOSTA, Osvaldo (1929): Motivos de crítica Juan Zorrilla de San Martín, Julio Herrera y Reissig, María Eugenia Vaz Ferreira, Montevideo, Palacio del Libro.

CróQuer Pedrón, Eleonora (2009): Escrito con rouge: Delmira Agustini (1886-1914). Artefacto cultural, Rosario, Beatriz Viterbo Editora.

EsCAJA, Tina, (2000): (Comp.) Delmira Agustini y el modernismo: nuevas propuestas de género, Rosario, Beatriz Viterbo Editora.

GIRÓN ALVARADO, Jacqueline (1995): Voz poética y máscaras femeninas en la obra de Delmira Agustini, Nueva York, Peter Lang. 
JimÉNEZ FARO, Luzmaría (1991): Delmira Agustini, manantial de la brasa, Madrid, Torremozas.

MEDINA VIAL, Jorge (1973): «Aspectos del Modernismo en el Uruguay», El 900 y el Modernismo en la Literatura uruguaya. Cuadernos de Literatura, 3: 57-71.

Montero Bustamante, Raúl (1905): El Parnaso Oriental. Antología de poetas uruguayos, Montevideo, s.n.

PARKER, William Belmont (1921): Uruguayans of to-day, The Hispanic Society of America Londres, Nueva York, http://archivos.liccom.edu.uy/ArchivoDePrensa/1.Belmont.pdf. [Consultado el 3 de septiembre de 2020].

PEREDA VALDÉS, Ildefonso (1960): «El modernismo en el Uruguay», Letras, 11, 204-214, http://dx.doi.org/10.5380/rel.v11i0.19915. [Consultado el 17 de octubre de 2020].

QUintana TEJERA, Luis (2006): «María Eugenia Vaz Ferreira. Aspiraciones esenciales. La noche y el alma de la poetisa. Soledad y abandono», en Lírica y narrativa latinoamericana en el siglo XX (Enfoques críticos) (México, Pensares Quehaceres), 17-61.

RoCCA, Pablo (2012): «Editar en el Novecientos (Orsini Bertani y algunos problemas de las culturas material y simbólica», Orbis Tertius 18/3, http://www.memoria.fahce.unlp.edu.ar/art_revistas/pr.5378/pr.5378.p df [Consultado el 4 de octubre de 2020].

SABAT ERCASTY, Carlos (1954): Retratos del fuego: María Eugenia Vaz Ferreira, Santiago, [s.n.].

SABBIA y OrIBE, María Herminia (1898): Aleteos, Montevideo, La Tribuna Popular.

SCARone, Arturo (1942): Diccionario de seudónimos del Uruguay, Montevideo, Claudio García \& Cía, $2^{\mathrm{a}}$ ed. (1937): Uruguayos contemporáneos. Nuevo Diccionario de datos biográficos $y$ bibliográficos, Montevideo, Casa A. Barreiro y Ramos.

SILVA, Clara (1972): Pasión y gloria de Delmira Agustini: su vida y su obra, Buenos Aires, Losada. 
VAZ Ferreira, Ma Eugenia (1924): La isla de los cánticos, Montevideo, Casa A. Barreiro y Ramos.

(1959): La otra isla de los cánticos, Montevideo, Impresora Uruguaya. 